\title{
Mercado de Trabalho: Revendo Conceitos e Aproximando o Campo da Saúde. A Década de 90 em Destaque
}

| ${ }^{1}$ Thereza Christina Varella, ${ }^{2}$ Célia Regina Pierantoni |

Resumo: Este artigo analisa o mercado de trabalho em saúde, em comparação com o mercado de trabalho brasileiro em geral. Apresenta inicialmente uma aproximação teórica sobre o tema, para sustentar o debate. Discute as características do mercado de trabalho em geral, buscando evidenciar se o quadro de desestruturação e desregulamentação verificado pode, em parte, ser reflexivo na configuração do setor saúde. Evidencia um movimento migratório de empregos públicos da esfera federal para a municipal, e também que, na década de 90, sobretudo o setor público se valeu de modalidades mais flexíveis para a contratação de profissionais de saúde.

Palavras-chave: mercado de trabalho; mercado de trabalho em saúde; recursos humanos em saúde.

\author{
${ }^{1}$ Enfermeira; doutora em \\ Saúde Coletiva; professora \\ assistente na Faculdade de \\ Enfermagem da UERJ; \\ pesquisadora na Estação de \\ Trabalho IMS/UERJ da Rede \\ Observatório de Recursos \\ Humanos em Saúde. Endereço \\ eletrônico: varella@ims.uerj.br \\ ${ }^{2}$ Médica; doutora em Saúde \\ Coletiva; professora adjunto \\ no Instituto de Medicina Social \\ da UERJ, coordenadora da \\ Estação de Trabalho IMS/UERJ \\ da Rede Observatório de \\ Recursos Humanos em Saúde. \\ Endereço eletrônico: \\ pieranto@infolink.com.br
}




\section{Introdução}

A institucionalização do Sistema Único de Saúde (SUS), a partir da Constituição Federal de 1988, fez visível a centralidade da questão dos recursos humanos como fundamental para sua implementação. A década de 90 foi marcada por cenários de transformações. Com o desafio de consolidar a democracia no plano da globalização, acompanhamos os esforços dos governos de realizar integração econômico-comercial e reformas administrativas. É consenso que o controle do déficit público, vinculado às exigências macroeconômicas, sempre esteve subjacente a tais esforços e reformas, incorporando, assim, as premissas de "menos Estado", representadas pela privatização, flexibilização e desregulação (ALMEIDA, 1997).

Essa década também é marcada por um período crítico na dinâmica do mercado de trabalho no Brasil, sobretudo pela evidente tendência ao desemprego, à terceirização acelerada das ocupaçōes urbanas, às metamorfoses do trabalho informal, refletindo, enfim, na perda de qualidade do emprego.

No contexto político de reforma do Estado, os recursos humanos em saúde, em que pese tenha sido delineada uma política de orientação igualitarista e regulamentadora, vêm passando por transformações em sua relação com as instituições prestadoras de serviços de saúde. Tais transformações se caracterizam especialmente por um processo de desregulamentação, verificado sobretudo pela substituição do emprego formal e assalariado por diversas outras modalidades de vinculação dos profissionais aos serviços.

Observam-se alternativas que transitam desde a contratação de profissionais autônomos, passando pelas formas de cooperativas, chegando ao extremo, segundo relatos, de contratos verbais. Tais modalidades vêm propiciando, entre outras consequiências, remunerações muito diversificadas, múltiplas jornadas e direitos diferenciados (PIERANTONI, 2006).

Este artigo procura oferecer uma análise da tendência nacional do mercado de trabalho em saúde, em comparação com o mercado de trabalho brasileiro em geral, buscando evidenciar se o quadro de desestruturação e desregulamentação verificado pode, em parte, ser reflexivo na configuração do setor saúde.

\section{Mercado de trabalho: uma aproximação teórica}

Para uma aproximação teórica do tema mercado de trabalho, optou-se por separar os termos e compreendê-los isoladamente, para depois entender sua conjugação. 
A noção de mercado, apesar de parecer senso comum e ser adotada na linguagem coloquial, não é tão clara assim. Pode adquirir significados diversos e requerer o esforço para sua elucidação. Uma delas estabelece oposição entre planejamento e mercado, o que na verdade colocava em oposição economias socialistas e economias ocidentais.

Nos anos 70, o caráter regulador do mercado predominou, sendo responsável pela alocação de recursos, distribuição de renda, equacionando a relação entre poupança e investimento. O objetivo era buscar eficiência econômica sem intervenção do Estado. O mercado é que deveria emitir sinais de preço. Qualquer perturbação seria por desequilíbrios passageiros, que logo se ajustariam pela lei da oferta e da demanda, voltando a prevalecer o equilíbrio.

Brunhoff (1991) estabelece duas concepçôes que predominaram sucessivamente: a ideologia laissez-faire e a dos novos economistas neoclássicos e monetaristas, em oposição ao período keynesiano. A ideologia do laissez-faire, anterior a 1914, teve como fundamento teórico a lei de Say, postulada no início do século XIX, a qual estabelece que não há ocorrência de superprodução na economia, pois pagamentos de fatores (salários, lucros, juros) que constituem custos de produção correspondem à renda necessária para a aquisição das mercadorias produzidas. Assim, a oferta cria sua própria demanda. De acordo com esta lei, não haveria superprodução geral e crise, mas desequilíbrios passageiros com flutuações econômicas de curto prazo se compensando naturalmente.

Após a Primeira Guerra Mundial e a Revolução Russa, o cenário mundial foi marcado por instabilidade das moedas e um grande desemprego. A Inglaterra perde a supremacia financeira em favor dos EUA; ocorre quebra do padrão-ouro e uma crescente organização sindical. Keynes, centrado na situação interna da Inglaterra e na conjuntura externa, anuncia o fim do laissez-faire e propõe a intervenção econômica do Estado, com o objetivo de conduzir a um regime de pleno emprego. A intervenção econômica do Estado se traduziu pelo estabelecimento de política econômica, por um conjunto de regras que afetam a economia nacional por meio de políticas financeira, monetária (ação sobre o crédito e o câmbio) e social (regulamentação de salários e de regimes de seguros) (BRUNHOFF, 1991).

$\mathrm{Na}$ essência, o objetivo do keynesianismo era manter o crescimento da demanda em paridade com o aumento da capacidade produtiva da economia, de forma suficiente para garantir o pleno emprego, mas sem excesso, pois isto provocaria um aumento da inflação. 
Tal mudança ideológica, anunciada pela Teoria Geral de Keynes, dominou as idéias econômicas no cenário mundial desde a Grande Depressão dos anos 30 até meados dos anos 70 , período em que a onda inflacionária, que começa a se estabelecer nos anos 60, tem mais expressão. O keynesianismo é citado como exemplo de uma "quase-tese" de que a evolução de teorias sociais (em particular econômicas) são reflexos de preocupaçóes enfrentadas pela sociedade em dados momentos da história (CARVALHO, 1999). O reformismo de Keynes se opõe ao laissez-faire, mas também rejeita as idéias marxistas (BRUNHOFF, 1991). Nem crise nem revolução, mas reforma do papel econômico do Estado com respeito ao sindicalismo operário.

O período que se sucedeu à Segunda Guerra Mundial brindou os países capitalistas desenvolvidos com 30 anos de desenvolvimento econômico, que parecem ter consagrado o keynesianismo e a oportunidade de estabelecimento de políticas econômicas. As despesas públicas desempenham papel indutor na economia e neste período se desenham as redes de proteção com o welfare state.

Em meados dos anos 60, delineia-se um período de retração da economia. $\mathrm{O}$ grande crescimento cedeu lugar à estagflação ${ }^{1}$ com alta dos preços e aumento do desemprego. Esse cenário cedeu lugar ao ressurgimento, na década de 70, da ideologia do Big Market, com o objetivo de impor aos agentes econômicos a disciplina do mercado.

A orientação econômica passa a seguir uma ótica monetarista, segundo a qual é possível manter a estabilidade da economia apenas com medidas monetárias, como o controle do volume de crédito, o aumento ou a diminuição da taxa de juros e redução de gastos governamentais. Neste contexto, o aumento do preço do petróleo na década de 70 , aliado à estagnação da economia e ao aumento da inflação, trouxeram para o cenário mundial uma grande crise econômica² .

Em síntese, a idéia de regulação pelo mercado, em escala internacional, tem a função de salvaguardar interesses financeiros capitalistas. A proposta não é remontar os diferentes momentos da economia mundial, uma vez que tais temas já foram tratados profundamente, por um sem-número de analistas especializados sob óticas variadas. A questão central é trazer o entendimento da alternância de concepçôes que vêm dominando o mercado, mesmo que reeditadas com ajustes conjunturais. A periodização adotada foi apenas a título de facilitar a explanação.

Para o outro pólo do termo - trabalho -, trataremos de analisar as conceituações sob diferentes óticas predominantes. Como categoria abstrata, o trabalho pode 
ser compreendido como esforço físico ou mecânico, como energia despendida por seres humanos, animais ou máquinas (CATTANI, 1997). Numa concepção geral, o trabalho é a forma pela qual o homem se apropria da natureza, transformando-a, tendo em vista construir as condições para sua sobrevivência. É uma atividade que altera o estado natural de materiais da natureza para aumentar sua utilidade. O trabalho humano tem como característica peculiar o fato de sua concepção anteceder a execução.

Outra concepção, com base na economia política, refere-se às formas que vem assumindo com o desenvolvimento das forças produtivas - forma concreta que assume em determinado modo de produzir mercadorias. Essa capacidade de adaptar ou transformar a natureza para atender às necessidades do homem produz um valor de uso que, em princípio, não tem por finalidade produzir excedentes para acumular riqueza. A capacidade para trabalhar é uma propriedade inalienável dos indivíduos, uma vez que é tradução da articulação de propriedades físicas, cognitivas e psicológicas do sujeito.

Entretanto, o modo de produção capitalista tem na sua essência a acumulação de capital. Sob a ótica capitalista, o trabalho passa a se constituir em valor de troca. O trabalhador detém a capacidade de trabalho e o capitalista domina as possibilidades (meios) de o trabalhador exercê-la. Mas o que o trabalhador vende e o capitalista compra não é uma quantidade de trabalho contratada, mas a força para trabalhar por um período de tempo contratado (BRAVERMAN, 1980).

Desse modo, o trabalho passa a embutir uma dupla finalidade: a de produzir valores de uso e valores de troca. Assume a condição de mercadoria a ser colocada no mercado, estando sujeito a sua regulação. Polanyi categoriza o trabalho como uma mercadoria "fictícia". Ainda segue analisando que, ao transformar a terra, o trabalho e dinheiro em mercadorias "fictícias", o mercado capitalista vai, pouco a pouco, corroendo a própria sociedade que lhe deu origem e condiçōes de surgir, e de se desenvolver. Busca evidências na história e na antropologia para mostrar que, na realidade, a atividade econômica sempre esteve, no passado, integrada em outras atividades de tipo social, e que a primazia do econômico, assim como a expansão e o predomínio do mercado, são fenômenos essencialmente modernos (POLANYI, 1980).

Com esse entendimento, pode-se encaminhar a discussão sobre mercado de trabalho sob alguns postulados: o trabalho quando se "coisifica" e passa a ter valor de troca no mercado, incorpora um fenômeno moderno que acompanhou o modo 
de produção capitalista; as leis do mercado, com suas nuanças conjunturais, estabelecem o preço do trabalho, ou seja, estabelecem o quanto vale a força de trabalho dos indivíduos.

A noção ortodoxa ${ }^{3}$ de mercado de trabalho é a de equilíbrio entre a oferta e a demanda de um fator de produção para um preço denominado salário (BRUNHOFF, 1991). O mercado de trabalho pode ser considerado um "termômetro" da economia. Tanto nos períodos de desenvolvimento como nos de crise, ele sofre variações que são medidas, principalmente, pelo desemprego.

Há consenso entre os teóricos da economia de que, por hipótese, existiria um "desemprego natural", que pode ser justificado por efeito de mudanças das técnicas de produção, do deslocamento dos processos de trabalho para fora do país, ou mesmo por modificação de hábitos sociais. Os economistas ortodoxos chamam de desemprego voluntário ${ }^{4}$ e Keynes aponta que o desemprego involuntário é um sinal de crise (BRUNHOFF, 1991).

Em oposição a esta acepção, está a concepção marxista, que revela uma assimetria dos agentes econômicos - donos do capital e trabalhadores - que define o preço da força de trabalho no mercado, ou seja, o salário. Nesta concepção, o que regula o valor do salário no mercado é a lei de oferta e demanda, que tem na base a "superpopulação relativa".

Por um lado, uma população de trabalhadores excedente é condição necessária para a acumulação capitalista, pois, com o desenvolvimento da produtividade do trabalho, cresce a força de capital que impulsiona novos ramos de produção. Nesses casos, grandes massas humanas têm de estar disponíveis para ocuparem novos postos sem prejudicar a escala de produção nos ramos já existentes. Assim, a indústria moderna e os novos métodos de produção dependeriam da transformação constante de uma parte da população trabalhadora em desempregados. Por outro, os movimentos dos salários não são determinados pelas variações do número absoluto da população trabalhadora, mas pela proporção variável em que essa população se divide em trabalhadores empregados e trabalhadores desempregados.

Estudo desenvolvido por Phillips em 1958 identificou uma relação negativa entre aumentos de salários e desemprego para a economia inglesa, através de uma longa série de dados (1861-1957). Dois anos depois, Samuelson e Solow reaplicam o exercício para os EUA, substituindo aumentos de salários por taxa de inflação e batizam a relação de Curva de Phillips. A relação empírica deu a impressão de 
que os países podiam escolher entre inflação e desemprego, ou seja, determinar sua posição na curva. A curva de Phillips seria um menu explorável de alternativas para a política macroeconômica. Qual seja, inflação baixa com desemprego alto, inflação alta com desemprego baixo, ou um ponto intermediário. A discussão de política econômica nos EUA na década de 60 teve muito a ver com a escolha do melhor ponto sobre a curva de Phillips. Naquela década, a taxa de desemprego dos EUA se reduziu à custa da elevação da inflação, como previa a curva de Phillips (GARCIA, 2005).

Entretanto, o choque do petróleo e a estagflação dos anos 70 deram uma nova versão para a curva de Phillips, que é atualmente aceita na macroeconomia. Na versão contemporânea da curva de Phillips, o desemprego afeta a variação da inflação, não o seu nível. O que pode ser escolhido é entre a taxa de desemprego e a variação na taxa de inflação. Nos dias de hoje, não se acredita que um desemprego elevado leve a uma inflação baixa, mas a uma redução na inflação (GARCIA, 2005). Acrescenta que um desemprego alto pode representar um desvio elevado da taxa natural ou apenas um aumento da taxa natural de desemprego. $\mathrm{O}$ modo de descobrir a resposta é olhar para a variação da inflação. Se esta estiver declinante, há indícios de que se trata de um desemprego elevado e não de uma taxa de desemprego natural mais alta.

O fato é que, na sociedade pós-industrial, ${ }^{6}$ o desemprego fica cada vez menos suscetível a medidas econômicas de reversão. Analistas vêem com pessimismo a possibilidade de retorno no mundo que não seja do pleno emprego, mas níveis de desemprego baixos (natural). Parece que o desemprego que se espalha sem mostrar sinais de retrocesso estaria fundamentalmente ligado a uma crise do trabalho da civilização pós-industrial.

\section{Mercado de trabalho no Brasil: a década de 90 em destaque}

A década de 90 se inicia com um comportamento da atividade econômica muito semelhante àquele que foi observado no início da década anterior, ou seja, com uma forte contração na taxa de crescimento e do PIB. Este movimento, de estagnação ou baixo crescimento, na verdade castiga continuamente o país nos últimos quase 30 anos. $\mathrm{O}$ direcionamento econômico mudou radicalmente de direção em relação ao observado na década de 70. Como resultado, o Brasil, país líder de crescimento, passou a apresentar taxas de expansão bastante inferiores às 
observadas nos países em desenvolvimento, com exceção de nossa parceira de Mercosul, a Argentina (DEDECCA, 2004).

O conjunto de políticas adotadas no primeiro ano da década de 90 engendrava um novo redirecionamento para a economia brasileira, através da promoção de uma política de abertura do mercado nacional aos produtos produzidos no exterior, bem como ao modo como o Estado brasileiro se relaciona com a sociedade. Essa abertura comercial, acompanhando o processo de globalização econômica, acelerou o movimento de reestruturação produtiva em função da necessidade de aumentar a competitividade industrial. A intensificação do ritmo de introdução de mudanças tecnológicas e organizacionais, principalmente no setor industrial, tinha como objetivo a elevação dos níveis de produtividade e qualidade dos produtos nacionais, com o intuito de fazer frente à concorrência internacional.

Tais medidas trouxeram conseqüências extremamente deletérias para o mercado de trabalho brasileiro, delineando um quadro de redução do emprego formal e ampliação do número de trabalhadores autônomos e dos empregados sem carteira assinada. De fato, o setor informal pode ser pensado como uma alternativa compensatória ao desemprego, ou seja, uma possibilidade para absorver a mãode-obra do setor formal da economia (FUENTES, 1997).

Os dados da OIT apontam o contínuo crescimento do trabalho informal na América Latina e no Brasil, em detrimento do trabalho regulamentado e/ou protegido por legislações específicas. Vale lembrar que o crescimento da informalidade do trabalho se inscreve em um período marcado pelo desemprego contínuo no mercado formal. No Brasil, o trabalho informal atingia sete milhões de pessoas no início da década de 90, contra dois milhões em 1980. Assim, o trabalho informal parece despontar como um recurso e abrigo dos trabalhadores face à escalada do desemprego (SILVA; BARBOSA, 2006).

Pochmann (1997) apresenta três visões que vêm predominando nos estudos sobre mercado de trabalho no Brasil nos 15 últimos anos. A primeira considera o problema do desemprego como decorrência das baixas taxas de crescimento da economia, o que poderia ser solucionado com a volta do desenvolvimento econômico, seja pela via formal, seja por uma flexibilização do mercado. A segunda visão é que não há propriamente desemprego no Brasil, uma vez que temos um mercado flexível capaz de gerar muitas ocupações, o que se justifica pelas baixas taxas de desemprego apontadas pelo IBGE, sendo a maior preocupação a qualidade 
das ocupações geradas. A terceira, com a qual se identifica o autor, é da dimensão estrutural do desemprego no funcionamento da economia, justificada tanto pelo abandono das políticas de industrialização quanto pelo processo abrupto de abertura comercial e de reestruturação empresarial em curso na década de 90.

Fuentes (1997) utiliza conceitos criados por Amoedo, segundo os quais o desemprego é considerado o custo de ajuste e o comportamento do setor informal como variável de ajuste. O entendimento é de que o setor informal foi necessário para que fossem desenvolvidas políticas de emprego que melhorassem a situação ocupacional.

$\mathrm{O}$ uso da expressão trabalho informal tem suas origens nos estudos realizados pela Organização Internacional do Trabalho (OIT) no âmbito do Programa Mundial de Emprego, de 1972. Ela aparece, de forma particular, no relatório a respeito das condições de trabalho no Quênia, na África. Constatou-se um grande contingente de trabalhadores vivendo de atividades econômicas consideradas à margem da lei e desprovidas de qualquer proteção ou regulação pública. $\mathrm{O}$ estudo verificou que havia uma parcela da população, composta por indivíduos sem qualificação, desempenhando toda a sorte de atividades por não encontrar espaço nas atividades tradicionais. Tais atividades foram denominadas atividades informais.

Uma das formas de classificação do trabalho informal utilizado pela OIT toma como referência a unidade econômica, caracterizada pela produção em pequena escala, pelo reduzido emprego de técnicas e pela quase inexistente separação entre o capital e o trabalho. Tais unidades também se caracterizariam pela baixa capacidade de acumulação de capital e por oferecerem empregos instáveis e reduzidas rendas. Refere também à completa falta de direitos sociais por parte dos trabalhadores (OIT, 1972).

Hart, citado por Fuentes, aponta como principal diferença entre setor formal e informal a existência de trabalho assalariado e trabalho autônomo, respectivamente (FUENTES, 1997). O estudo da OIT serviu de base para se estabelecer modelos dualistas, ou seja, de um mercado de trabalho segmentado em um setor tradicional ou de subsistência, e um setor moderno. Entretanto, não há consenso sobre a representação do setor informal e seus efeitos no mercado de trabalho.

Para Cacciamali (2000), o setor informal é, de maneira equivocada, um conceito definido para mercado de trabalho, em vez de constituir-se como uma categoria analítica da estrutura produtiva. Camargo (1996) associa o setor informal à perspectiva de flexibilidade do mercado de trabalho, ou seja, à capacidade de 
adaptação do mercado de trabalho a choques exógenos, mantendo pequenas variaçôes na taxa de desemprego aberto ${ }^{7}$.

A propósito, de acordo com Lagos (1994) e Filgueiras-Rauch (2000), a flexibilidade do mercado de trabalho pode ser classificada em:

- De custos laborais e financeira - consiste na revisão de regras trabalhistas e na criação de instrumentos de remuneração para se adaptar às necessidades de produção, como gratificações e complementos salariais.

- Numérica - que pode ser subdividida em externa, quando a empresa realiza ajustes no seu quadro de trabalhadores, ou flexibilidade interna ou temporal, quando implica variação no número de horas trabalhadas, sem mudanças de efetivos de trabalhadores, ou seja, na quantidade de empregos.

- Funcional - refere-se à mobilidade dos trabalhadores dentro da empresa com a reorganização de postos de trabalho diante de modificações no volume de trabalho ou por introdução de novas tecnologias.

Apesar de haver controvérsia, o conceito de trabalho informal utilizado pelas estatísticas oficiais do IBGE está atrelado ao tipo de posição na ocupação: aquele cujos ocupantes são trabalhadores por conta própria ou trabalhadores sem carteira assinada.

Sabe-se que boa parcela do setor informal é representada por trabalhadores com baixa qualificação e pouca escolaridade que, em tempos de crise econômica e, mais especificamente, nas mudanças de organização do processo produtivo, não encontram espaço no setor formal (que vem exigindo cada vez mais profissionais polivalentes e com maior nível educacional) e passam a se sujeitar a situaçôes cada vez mais precárias, com baixos salários, péssimas condições de trabalho, perda de direitos trabalhistas, extensão da jornada de trabalho, entre outras. Por outro lado, encontra-se também no setor informal uma parcela de trabalhadores qualificados que não se sujeitaram aos ajustes salariais impostos pelo mercado e optaram por trabalhar por conta própria, em função da possibilidade de aumentar seus ganhos.

Pochmann (1997) aponta que no Brasil, entre 1990 e 1992, mais de dois milhões de postos de trabalhos foram queimados por força da política recessiva do Governo Collor, sem maiores preocupações com seus impactos sociais. No período compreendido entre 1993 e 1997, pode-se observar uma recuperação no nível de atividade econômica, sem, entretanto, ser verificada a ampliação do nível de emprego assalariado. Acrescenta que, além do fechamento de empresas, a internacionalização e a privatização de outras, ocorre um processo de reestruturação 
empresarial, com a racionalização da produção e o aumento da produtividade, acompanhados por aumentos da jornada total de trabalho, seja através de maior uso de horas extras, seja através de ocupações sem registro e por conta própria que operam, em geral, com tempo de trabalho muito intensivo.

O Brasil experimentou, no final de século passado, um desemprego que talvez nunca tenha sido observado. Seu crescimento, tanto em termos relativos quanto absolutos, tem sido acompanhado pela crescente deterioração das condições de trabalho. Tal aumento do desemprego é generalizado, tanto em termos de grupos sociais, como em termos setoriais. Para ilustrar, a maior taxa de crescimento ${ }^{8}$ do número de desempregados é a do grupo social com maior escolaridade engenheiros, advogados e economistas desempregados. A redução do número de postos de trabalho ocorreu todos os anos a partir de 1995, e atingiu todos os setores, inclusive aqueles com maior intensidade no uso de trabalho (construção civil e comércio) (MATTOSO, 1999).

Pode-se observar na tabela abaixo que a taxa de desemprego aberta foi crescente durante toda a década de 90, tendo crescimento mais expressivo nos dois últimos anos.

Tabela 1 - Taxa de desemprego aberto. Brasil, 1991-2002

\begin{tabular}{|c|c|c|c|c|c|c|c|c|c|c|c|c|c|}
\hline \multirow{2}{*}{ Ano } & \multicolumn{10}{|c|}{} & \multicolumn{10}{|c|}{ JAN } & FEV & MAR & ABR & MAI & JUN & JUL & AGO & SET & OUT & NOV & DEZ & Média \\
\hline 1991 & 5,7 & 5,9 & 6,4 & 6,1 & 6,2 & 5,3 & 4,1 & 4,4 & 4,7 & 4,7 & 4,9 & 4,6 & 5,3 \\
\hline 1992 & 5,3 & 6,8 & 6,8 & 6,6 & 7 & 5,5 & 5,7 & 6,3 & 6,2 & 6,3 & 6,3 & 5 & 6,2 \\
\hline 1993 & 6,5 & 6,3 & 6,3 & 6,6 & 5,7 & 5,3 & 5,6 & 5,7 & 5,5 & 5,4 & 5,2 & 5 & 5,8 \\
\hline 1994 & 5,9 & 5,9 & 6,3 & 5,8 & 5,6 & 5,9 & 5,8 & 5,9 & 5,3 & 4,9 & 4,3 & 3,8 & 5,5 \\
\hline 1995 & 4,7 & 4,5 & 4,8 & 4,7 & 4,7 & 4,9 & 5,2 & 5,2 & 5,5 & 5,4 & 5,2 & 5 & 5,0 \\
\hline 1996 & 5,6 & 6,2 & 6,7 & 6,5 & 6,3 & 6,3 & 6 & 6 & 5,6 & 5,4 & 4,9 & 4,3 & 5,8 \\
\hline 1997 & 5,5 & 5,9 & 6,3 & 6,1 & 6,4 & 6,8 & 6,5 & 6,4 & 6,1 & 6,2 & 5,8 & 5,5 & 6,1 \\
\hline 1998 & 7,9 & 8,4 & 8,9 & 8,9 & 8,9 & 8,7 & 8,7 & 8,5 & 8,3 & 8 & 7,8 & 7,1 & 8,3 \\
\hline 1999 & 8,4 & 8,5 & 8,9 & 8,8 & 8,4 & 8,4 & 8,1 & 8,3 & 8 & 8,2 & 8 & 7,1 & 8,3 \\
\hline 2000 & 8,4 & 8,9 & 9 & 8,5 & 8,4 & 8,1 & 7,9 & 7,8 & 7,3 & 7,5 & 6,8 & 5,6 & 7,9 \\
\hline 2001 & 6,3 & 6,4 & 6,9 & 7 & 7,6 & 7 & 6,7 & 6,8 & 6,8 & 7,1 & 7 & 6,4 & 6,8 \\
\hline 2002 & 6,8 & 7 & 7,1 & 7,6 & 7,7 & 7,5 & 7,5 & 7,3 & 7,5 & 7,4 & 7,1 & 5,2 & 7,1 \\
\hline
\end{tabular}

Fonte: IBGE, Diretoria de Pesquisas, Departamento de Emprego e Rendimento. Pesquisa Mensal de Emprego. 
Mattoso (1999) acrescenta que também tem havido piora significativa das condições de trabalho. Os dados são conclusivos a respeito do aumento do trabalho temporário, por tempo determinado e sem renda fixa. A precarização do trabalho reflete o fato de que dois em cada cinco brasileiros encontram ocupação em atividades informais. Verifica-se que nas grandes cidades três em cada cinco brasileiros estão desempregados ou na informalidade. Estima-se, então, que cerca de 24 milhões de pessoas estariam fora do mercado formal de trabalho, enquanto mais de 10 milhões estariam desempregadas.

Para o mercado de trabalho brasileiro, a década de 90 também parece ter sido uma década perdida, marcada pelo desemprego, pela flexibilização do mercado de trabalho e grande aumento da parcela da população submetida a modalidades de trabalho informal.

A taxa de desemprego aberto a partir de 2000 apresenta um recuo, como pode ser visto na tabela 1 . Relatório do Banco Central, de 2005, com base nos dados do IBGE, mostra que o desemprego ostentou nesse ano patamares menores que 2002, apresentando tendência de queda para os próximos meses. Acrescenta ainda que os dados do Ministério do Trabalho confirmam o comportamento favorável de geração de empregos.

Tabela 2 - Taxa de desemprego aberto. Brasil, 2005-2006

\begin{tabular}{|c|c|c|}
\hline \multicolumn{2}{|c|}{ Período } & Taxa média \\
\hline 2005 & Jan & 10,2 \\
\hline & Fev & 10,6 \\
\hline & Mar & 10,8 \\
\hline & $\mathrm{Abr}$ & 10,8 \\
\hline & Mai & 10,2 \\
\hline & Jun & 9,4 \\
\hline & Jul & 9,4 \\
\hline & Ago & 9,4 \\
\hline & Set & 9,6 \\
\hline & Out & 9,6 \\
\hline & Nov & 9,6 \\
\hline & Dez & 8,3 \\
\hline 2006 & Jan & 9,2 \\
\hline
\end{tabular}

Fonte: IBGE. 
Entretanto, os dados apresentados na tabela acima, apesar de mostrarem uma tendência decrescente, mostram uma média ainda superior às observadas no final da década passada. Para a economista Ceci Juruá, as previsões para 2006 não são otimistas. Em resenha sobre o período que se segue, observa, com base na configuração da economia nacional, três movimentos:

[...] reconcentração de renda em favor do capital rentista e em detrimento dos rendimentos do trabalho; endividamento de amplos segmentos da economia brasileira e, principalmente, do Governo federal; desindustrialização e desnacionalização do sistema produtivo local.

Acrescenta que esses três movimentos são complementares e atuam no sentido de ampliar a dominação das finanças internacionais sobre a economia e a sociedade no Brasil. A reconcentração de renda e o desemprego industrial limitam a expansão do consumo doméstico e propiciam o endividamento das famílias; a estagnação do consumo fragiliza as finanças públicas e limita a modernização dos negócios privados voltados para o mercado interno, provocando desequilíbrios econômico-financeiros que, aliados às elevadíssimas taxas de juros, propiciam o endividamento das empresas e as conduzem à falência ou à desnacionalização. (JURUÁ, 2006, s/p).

Dedecca (2004) afirma que não existe experiência mundial que comprove um elevado grau de desenvolvimento e dinamismo econômico sem um mercado interno forte, nem tampouco sem uma distribuição de renda com uma participação dos salários inferior a 50\%. Coloca que se o governo atual conseguir tal façanha, mantendo a atual política econômica, estaremos frente a um verdadeiro milagre.

Como se comporta o mercado de trabalho em saúde neste cenário? O quadro verificado no mercado de trabalho em geral no Brasil é reflexivo na saúde?

\section{O mercado de trabalho em saúde nos anos 90}

O setor saúde, como parte do setor terciário, possui atributos que são estruturais para o entendimento deste segmento: gera produtos não-materiais, produção e consumo ocorrem simultaneamente e a incorporação tecnológica na saúde não produz economia de força de trabalho; ao contrário, passa a demandar novas ocupações, configurando o setor saúde como intensivo de mão-de-obra.

No mercado de trabalho formal, o segmento da saúde apresentou crescimento na última década. A importância do emprego e da massa salarial gerada em atividades de saúde representou no final dos anos 90 cerca de $10 \%$ do equivalente na economia em geral (GIRARDI; CARVALHO, 2002). 
Dedecca (2001) assinala que o mercado de trabalho em saúde teve, na década de 90, uma dinâmica específica, com crescimento do emprego, tanto público como privado. Mostra que no núcleo ${ }^{9}$ do setor saúde, entre 1992 e 1997, foram criadas cerca de 300 mil ocupações, e em torno de 450 mil ocupaçóes em atividades afins. Tal crescimento representa um incremento de aproximadamente 10\%, observado na população ocupada não-agrícola.

É consensual que a implementação do SUS foi o grande alavancador deste mercado, tanto pela expansão da rede pública, em especial na esfera municipal, quanto da rede privada contratada, que indubitavelmente gerou novos postos de trabalho. O papel da política de atendimento à saúde interfere positivamente no desempenho do mercado de trabalho nacional (DEDECCA, 2001).

De acordo com Girardi e Carvalho (2002), com base nos dados dos registros administrativos do Ministério do Trabalho (RAIS-CAGED), a estimativa é de que o setor saúde detenha 2,5 milhões de vínculos formais de emprego, dos quais 1,7 milhão no núcleo do setor. Tais empregos representam $10 \%$ da economia formal do país.

Em relação ao estoque, com base nos dados dos conselhos profissionais, estimase um quantitativo de 1,7 milhões de profissionais de saúde e 930.189 vínculos de empregos formais para esses profissionais, segundo os registros da RAIS. Em dezembro de 2000, dos 2,5 milhões de vínculos formais do macrossetor saúde, cerca de $70 \%$ destes estavam em estabelecimentos de serviços de saúde (GIRARDI; CARVALHO, 2002).

Tabela 3 - Comparação de indicadores gerais dos mercados de trabalho dos profissionais de saúde empregados no setor formal. Brasil, 1995-2000

\begin{tabular}{|c|c|c|c|c|c|c|}
\hline Ano & $\begin{array}{c}\text { No de } \\
\text { vínculos } \\
\text { Ativos }\end{array}$ & $\begin{array}{c}\text { \% de } \\
\text { participação } \\
\text { Feminina }\end{array}$ & Idade média & $\begin{array}{c}\text { Salário } \\
\text { médio } \\
\text { (em salários } \\
\text { mínimos) }\end{array}$ & $\begin{array}{c}\text { Horas } \\
\text { semanais } \\
\text { contratadas }\end{array}$ & $\begin{array}{c}\text { Tempo } \\
\text { médio de } \\
\text { emprego } \\
\text { em meses }\end{array}$ \\
\hline 1995 & 816.838 & 72,4 & 37 & 6,7 & 35 & 75 \\
\hline 2000 & 930.189 & 73,3 & 38 & 6,5 & 36 & 84 \\
\hline
\end{tabular}

Fonte: MT/Adaptado de Girardi e Carvalho (2004). 
A título de ilustração, conforme pode ser observado na tabela 3, o estoque de vínculos ativos da saúde cresceu $11,4 \%$ em cinco anos, o que pode ser considerado um excelente desempenho do setor num período em que as taxas de desemprego cresceram. Entretanto, apesar de pouco expressiva, observa-se uma pequena redução do salário médio e um discreto aumento da média de horas semanais contratadas. Se comparados ao salário médio, entre janeiro de 2004 e janeiro de 2005, no conjunto das ocupações da saúde a queda é bem mais acentuada, ficando o salário médio em torno de 4,3 salários mínimos, conforme pode ser observado no gráfico 1, que apresenta a variação salarial de seis ocupaçōes da saúde. O fato é que, apesar do crescimento do emprego no setor, este não vem sendo acompanhado de ganho salarial para os trabalhadores com vínculos formais.

\section{Gráfico 1 - Evolução do salário médio por ocupação. \\ Brasil, Janeiro 2004 - janeiro 2005}

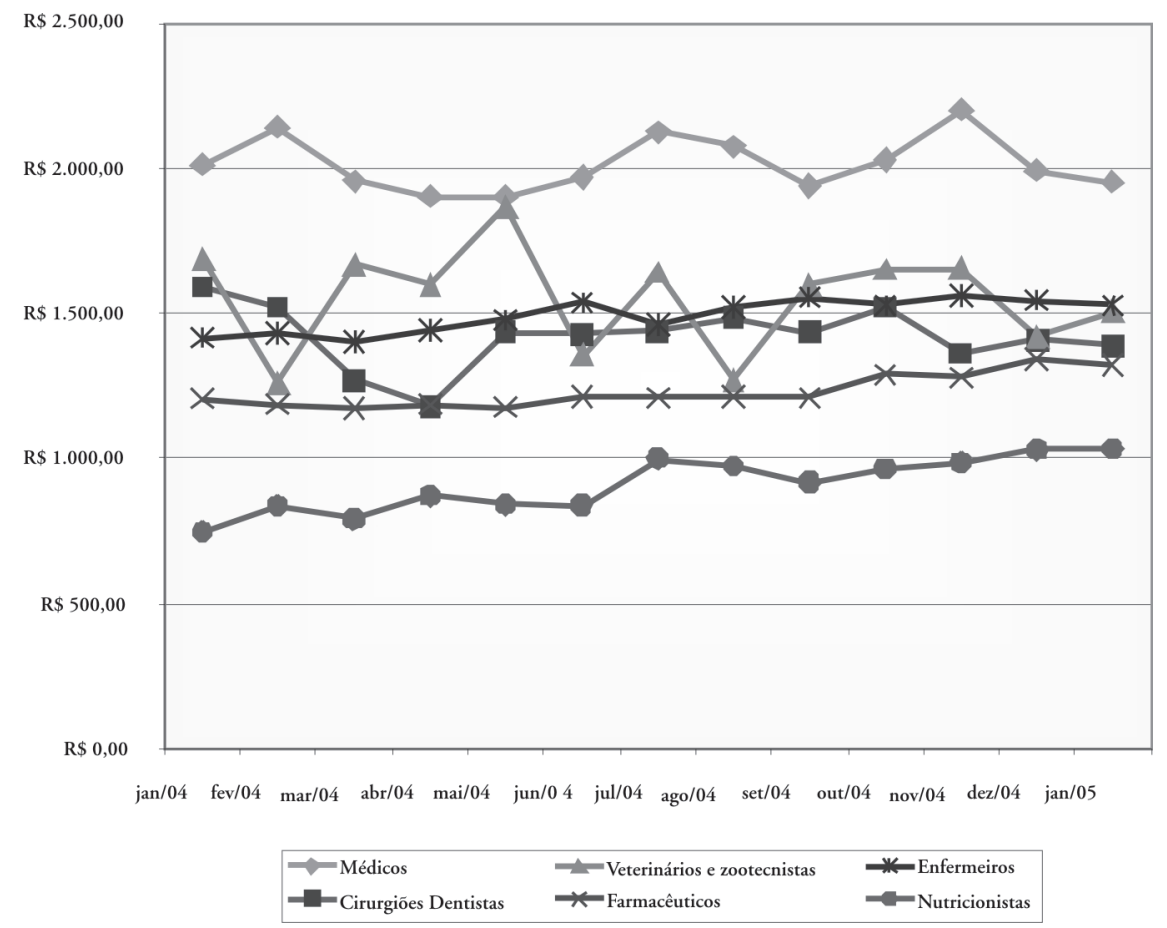

Fonte: MT/Nescon-UFMG. 
No que se refere ao segmento público, houve movimento singular decorrente do processo de descentralização das ações de saúde. A esfera municipal, em 1999, passou a deter a gestão de $92 \%$ dos estabelecimentos públicos (estatais) de saúde no país, restando ao nível federal 2\%, e ao estadual, 6\% (SILVA; COSTA, 2002). Este mesmo movimento pode ser observado com o crescimento do emprego público, que se dá de forma expressiva no nível municipal, apresentando variação positiva no período de 1992 a 2005, de mais de 700\%. Vale ressaltar que, em 2005, a esfera federal passa a deter apenas $7 \%$ dos empregos públicos do país, conforme demonstrado no gráfico 2 .

\section{Gráfico 2 - Empregos públicos de saúde segundo esfera administrativa. Brasil, 1992-2005}

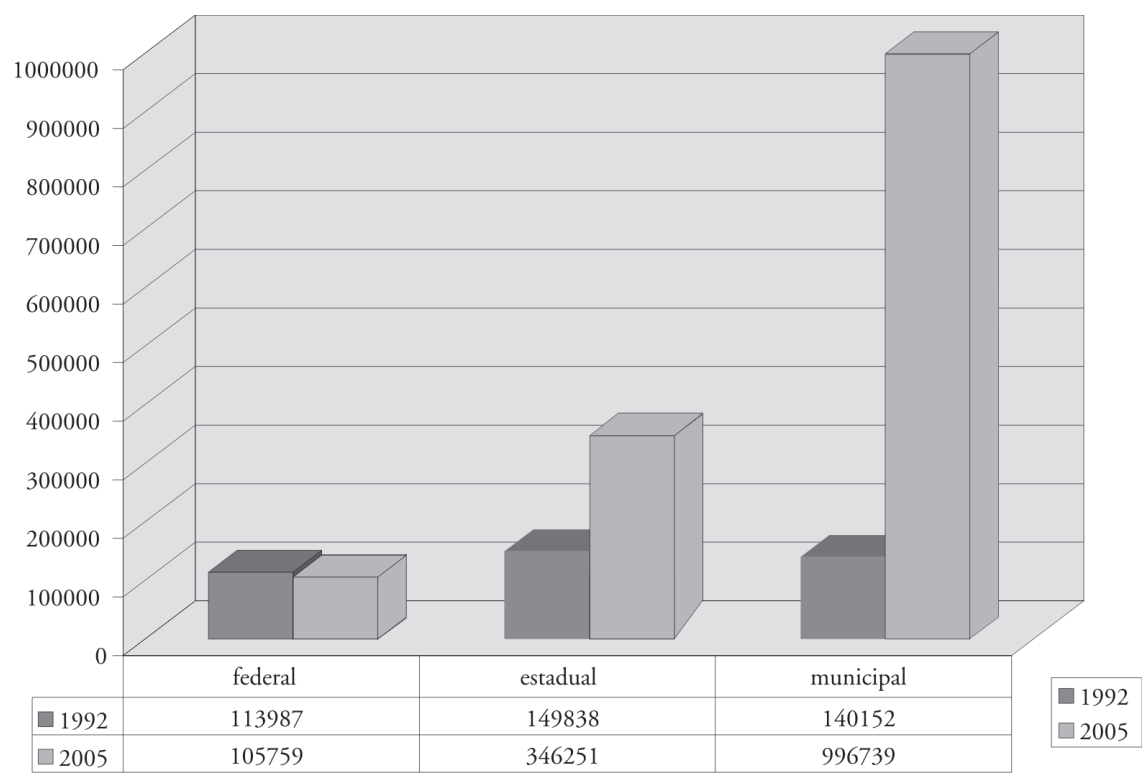

Fonte: IBGE/MAS.

Não há consenso em relação ao segmento do setor saúde que detém o maior número de empregos. De acordo com os dados da RAIS, o setor privado é responsável pelo maior número de empregos formais $(52,4 \%)$ de profissionais de saúde no núcleo do setor. Já nas atividades afins, é o setor público que detém o maior número de vínculos (52,2\%) (DEDECCA, 2001). Já pelos dados da AMS/ IBGE, o dinamismo do setor pode ser atribuído, na década de 90, ao incremento de postos do setor público estatal, alavancados pela implementação do SUS, que 
se deu na ordem de $36 \%$ contra $26,5 \%$ do setor privado. Em 2005, do total de empregos do setor saúde, $56 \%$ eram públicos. Sob uma análise mais qualitativa, pode-se observar que o segmento público do setor saúde concentra um maior contingente de profissionais com escolaridade e maior qualificação. Por exemplo, no setor privado há uma maior proporção de pessoal de enfermagem que no setor público, enquanto a proporção de médicos e enfermeiros é maior no público. Os profissionais com nível de escolaridade superior representam $44,6 \%$ no setor público enquanto que no privado somam 19,5\% (DEDECCA, 2001).

Parece haver consenso que, ao contrário do observado no mercado de trabalho em geral na década de 90, o setor saúde apresentou dinamismo positivo, com expansão de postos de trabalhos e aumento de ocupações no setor. Pode-se argumentar que, em uma perspectiva macroeconômica, o setor poderia ter um potencial de abrandamento, por meio da geração de emprego e renda, do impacto social das tendências de crescimento do desemprego observadas nesta década. Entretanto, alguns estudos como os de Machado (2000) e Girardi e Carvalho (2003), realizados para analisar o período, puderam mostrar que o setor saúde não esteve tão imune aos efeitos dos impactos dos processos de desregulamentação e desestruturação do mercado de trabalho brasileiro. Tais impactos foram observados através de mudanças ocorridas nas relações contratuais, com o aumento de vínculos informais, principalmente no setor público.

Os gestores municipais e estaduais, no transcorrer dos anos 90, vêem-se diante de escolhas paradoxais. Se, por um lado, as reformas preconizadas para diminuição dos gastos públicos e da dívida interna impuseram medidas restritivas com o gasto com pessoal ${ }^{10}$, por outro, a necessidade de expansão da rede de serviços de saúde com o processo de descentralização apontava para a premência de abertura de novos postos de trabalho. O Programa de Saúde da Família pode ser usado como exemplo emblemático da utilização de "novas" formas contratuais (por meios mecanismos de terceirização e outras modalidades de contratos informais) para a inserção de trabalhadores no sistema de saúde.

Alguns gestores locais passaram a defender o expediente de contratação de profissionais de saúde por meio de empresas terceirizadas e cooperativas, alegando que tais mecanismos fortaleciam a governabilidade e melhoravam a qualidade da assistência nas unidades de saúde, uma vez que não havia mais problemas com a falta e a reposição de pessoal nos serviços. 
Os resultados da pesquisa "Agentes Institucionais e Modalidades de Contratação de Pessoal no Programa de Saúde da Família no Brasil”" (GIRARDI; CARVALHO, 2003) mostram que os principais agentes contratantes para o PSF são as prefeituras (em torno de $80 \%$ para todas as categorias), nas quais as formas de contratação temporária de trabalho e o vínculo de prestação de serviços predominam amplamente sobre todas as outras formas de contrato nos municípios pesquisados.

Silva e Costa (2002) mostram, com base no relatório do NEPP (2000), que $22 \%$ e $25 \%$ dos municípios brasileiros adotavam a forma contratual estatutária para a inserção de médicos e enfermeiros, respectivamente, na atenção básica. A terceirização por empresas e cooperativas foi registrada como principal tipo de contratação de médicos, em $18 \%$ dos municípios e, para enfermeiros, $12 \%$, na Região Sul do país. Na Região Centro-Oeste, 38\% dos municípios informam utilizar a modalidade de contrato de autônomo para médicos e 33\% utilizam a mesma modalidade para contratar enfermeiros e odontólogos.

Entretanto, pesquisa ${ }^{11}$ recente sobre a capacidade gestora de recursos humanos em municípios com mais de 100 mil habitantes mostrou que, a partir do ano $2000,80,0 \%$ dos gestores entrevistados declararam ter realizado concurso público como forma de recrutamento e seleção de pessoal, o que poderá influenciar uma mudança na configuração do mercado no segmento público municipal.

\section{Gráfico 3: Ano de realização do último concurso público segundo a regiáo do país. Brasil, 2004}

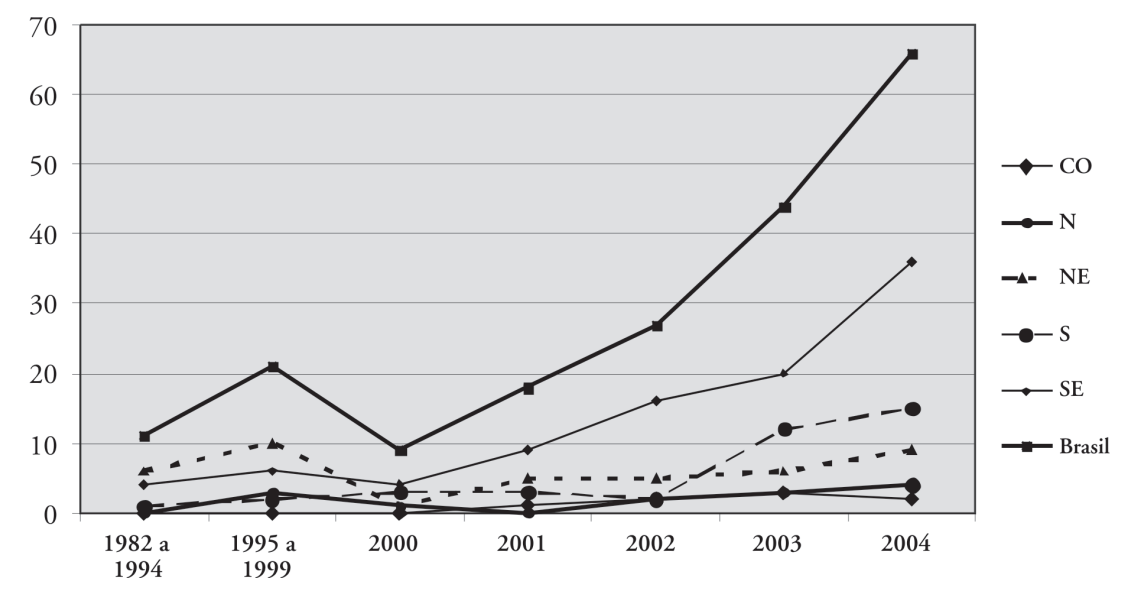

Fonte: ROREHS/IMS-UERJ/NESCON-UFMG. Capacidade gestora de recursos humanos em instâncias locais de saúde em municípios com população superior a 100 mil habitantes (BRASIL, 2004). 


\section{Considerações finais}

O panorama apresentado pode apontar algumas pistas para a compreensão das questōes anteriormente levantadas. Em primeiro lugar, o fato de o mercado de trabalho em saúde, como já referido, apresentar um comportamento diferenciado com aumento de postos de trabalho e de pessoal ocupado no setor. Os estudos são insuficientes para avaliar se há, e como se comporta, o desemprego no setor. $\mathrm{O}$ quadro de desestruturação e desregulamentação do mercado de trabalho em geral pode, em parte, ser reflexivo na configuração do setor saúde, uma vez que na década de 90, principalmente o setor público valeu-se de modalidades mais flexíveis para a contratação de profissionais de saúde.

Entretanto, há indicativos de mudança neste cenário, quando analisado a partir de 2000, seja pela própria orientação política da SEGETS/MS, em 2003, de "desprecarização" do trabalho no SUS, seja pelo papel do Ministério Público, que vem pressionando estados e municípios a cumprirem o princípio constitucional de ingresso no serviço público mediante concurso público. Mais ainda, que a informalidade aplicada, em especial ao PSF, na segunda metade da década de 90 e no setor público, mais que cumprir um papel como variável de ajuste da economia, foi acima de tudo um engendramento para burlar as amarras jurídicas e ao mesmo tempo atender às demandas expansionistas do sistema.

Estudos mais conclusivos precisam ser realizados para avaliar se as políticas públicas levadas a efeito nos últimos anos refletiram na configuração do mercado de trabalho em saúde revertendo as tendências de desregulamentação evidenciadas na década passada, especialmente no setor público.

\section{Referências}

ALMEIDA, C. Crise econômica, crise do welfare e reforma sanitária. In: GERSCHMAN, S.; VIANNA, M. L. W. (Org.). A miragem da pós-modernidade: democracia e políticas sociais no contexto da globalização. Rio de Janeiro: Fiocruz, 1997. p. 177-200.

ANTUNES, R. Os sentidos do trabalho: ensaio sobre a afirmação e a negação do trabalho. São Paulo: Boitempo Editorial, 2000. 258p.

ANTUNES, R. Adeus ao trabalho? Ensaio sobre as metamorfoses e a centralidade do mundo do trabalho. São Paulo: Cortez, 2002. 200p.

. O caráter polissêmico e multifacetado do mundo de trabalho. Trabalho, educação e saúde.

Rio de Janeiro, v. 1, n. 2, p. 229-237, set. 2003. 
BENJAMIN, C. Desemprego em uma abordagem teórica: notas sobre neoclássicos, Keynes e Marx. Disponível em: <http://www.desempregozero.org.br/artigos/desemprego_em_uma_ abordagem_teorica.pdf>. Acesso em: 23 out. 2004.

BOBBIO, N. Dicionário de Política. Brasília: UnB, v. 1, 1995. 666 p.

BÓGUS, L.; PAULINO, A. Y. (Orgs.). Politicas de emprego, politicas de população e direitos sociais. São Paulo: EDUC, 1997. 250p.

BRASIL. Banco Central do Brasil. Relatório de inflação. Brasília, v. 7, n. 3, set. 2005. Disponível em: <http://www.bcb.gov.br/htms/relinf/port/2005/09/ri200509cap.pdf>. Acesso em: fev. 2006.

BRAVERMAN, H. Trabalho e capital monopolista: a degradação do trabalho no século XX. Rio de Janeiro: Zahar, 1980.379p.

BRUNHOFF, S. A hora do mercado: crítica do liberalismo. São Paulo: Unesp, 1991. 182p.

CACCIAMALI, M. C. Proceso de informalidad y sector informal: reexamen de una discusión. Rev. Venez. de Econ. y Ciencias Sociales. Caracas, v. 6, n. 3, p. 95-110, 2000.

CAMARGO, J. M. Flexibilidade e produtividade do mercado de trabalho brasileiro. In (Org.). Flexibilidade do mercado de trabalho no Brasil. Rio de Janeiro: FGV, p. 11-45, 1996.

. (Org.). Flexibilidade do mercado de trabalho no Brasil. Rio de Janeiro: FGV, 1996. 244 p.

CARLEIAL, L.; VALLE, R. (Org.). Reestruturação produtiva e mercado de trabalho no Brasil. São Paulo: Hucitec, 1997. 507p.

CARVALHO, F. J. C. Mercado, estado e teoria econômica: uma breve reflexão. Econômica, Niterói, v. 1, n. 1, p. 9-25, 1999.

CATTANI, A. D. (Org.). Trabalho e tecnologia. Dicionário crítico. Petrópolis: Vozes, 1997. p. 292.

DEDECCA, C. S. Brasil, o novo governo e o desenvolvimento social. 2004 mimeo em pdf. Disponível em: <http://www.ie.ufrj.br/aparte/pdfs/cdedecca_governoedesenvolvimentosocial.pdf? PHPSESSID=cf66c46ceafe0fdb87092a63800ece02>. Acesso em: 7 out. 2005.

- Crescer sem mercado interno forte e sem uma distribuição de renda menos concentrada será um verdadeiro milagre. 2004. Disponível em: <http://www.ie.ufrj.br/aparte/pdfs/ cdedecca_distribuicao_de_renda_principios_2004.pdf?PHPSESSID=0fa5584dd4e17f4 e230ce9616df59c9d>. Acesso em: 7 out. 2004.

DEDECCA, C. S.; PRONI, M. W.; MORETO, A. O trabalho no setor de atenção à saúde. In: NEGRI, B.; GIOVANNI, G. Brasil: radiografia da saúde, 2001. p. 175-216.

FILGUEIRAS-RAUCH, M. J. As novas formas de emprego atípicas: reflexões sobre o caso alemão. 2000. Disponível em: <http://www.dgct.mts.gov.pt/estudos_emprego.htm>. Acesso em: 3 ago. 2004.

FUENTES, M. R. Setor informal e reestruturação produtiva: uma alternativa de emprego nos anos 90? In: CARLEIAL, L.; VALLE, R. (Org.). Reestruturação produtiva e mercado de trabalho no Brasil. São Paulo: Hucitec, 1997, p. 357-374. 
GARCIA, M. G. P. O real dilema entre inflação e crescimento. 2005. Disponível em: <http:// www.econ.puc-rio.br/Mgarcia/Artigos/Artigos\%20Valor/050415\%20Real\%20dilema.pdf>. Acesso em: 15 abr. 2005.

GIRARDI, S. N.; CARVALHO, C. L. Configurações do mercado de trabalho dos assalariados em saúde no Brasil. Formaçāo, Brasília, v. 2, n. 6, p. 15-35, 2002.

Mercado de trabalho e regulação das profissões de saúde. In: NEGRI, B.; FARIA, R.; VIANA, A. L. D. (Org.). Recursos humanos em saúde-politica, desenvolvimento e mercado de trabalho. Campinas: Unicamp, 2002. p. 221-251.

. Contratação e qualidade do emprego do programa de saúde da família no Brasil. In: FALCÃO, A. et al. (Org.). Observatório de recursos humanos em saúde no Brasil: estudos e análises. Rio de Janeiro: Fiocruz, 2003. p. 157-190.

. Configuraçốes do mercado de trabalho dos assalariados em saúde no Brasil. In: FALCÃO, A. et al. (Org.). Observatório de recursos humanos em saúde no Brasil: estudos e análises. v. 2. Rio de Janeiro: Fiocruz, 2004. p. 121-137.

INSTITUTO BRASILEIRO DE GEOGRAFIA E ESTATÍSTICA. Disponível em: <http:// www.ibge.gov.br/home/estatistica/indicadores/trabalhoerendimento/pme_nova/ retrospectiva_pme.pdf>.Acesso em: 30 jun. 2005.

JURUÁ, C. V. As previsóespara o novo ano de 2006. Disponível em: <http://www.desempregozero.org.br/ artigos/as_previsoes_para_o_novo_ano_de_2006.php>.Acesso em: jan. 2006.

LAGOS, R. A. Qué se entiende por flexibilidad del mercado de trabajo? Revista de la CEPAL, n. 64, p. 81-95, dic. 1994.

MACHADO, M. H. Perfil dos médicos e enfermeiros do Programa Saúde da Família no Brasil: Relatório Final. Brasília: Ministério da Saúde, 2000, v. 1, 146 p.

MASI, Domenico di (Org.). A sociedade pós-industrial. São Paulo: Senac, 2000. 443 p.

MATTOSO, J. O Brasil desempregado: como foram destruídos 3 milhões de empregos no Brasil nos anos 90. Brasília: Fundação Perseu Abramo, 1999. 48p.

OIT. Employment, income and equality: a strategy for increasing employment in Kenya. Ginebra: OIT, 1972.

PEREIRA, L. C. B. Economia formal e economia política, 1970. Disponível em: <http:// www.bresserpereira.org.br/papers/1970/90-EconomiaFormal\&EconomiaPolitica.pdf $>$. Acesso em: 13 out. 2004.

PEREIRA, L. C. B. Ortodoxos e histórico-institucionalistas. IN: Encontro Nacional da Sociedade Brasileira de Economia Política, 10. Campinas, 2005. Anais... Disponível em: <http:// www.bresserpereira.org.br/Works/SmallPapers/14.Lawson-Ortodosx \&HistoricoInstitucionalistas.pdf>. Acesso em: 13 out. 2004. 
PIERANTONI, C. As reformas do Estado, da saúde e recursos humanos: limites e possibilidades. Ciência e Saúde Coletiva. Rio de Janeiro, v. 6, n. 2, p. 341-360, 2001.

PIERANTONI, C.; VARELLA, T. C. Classificação Brasileira de Ocupações 2002: perspectivas para análise do mercado de trabalho em saúde com o foco na enfermagem. Formação, Brasília, v. 2, n. 6, p. 55-69, 2002.

PIERANTONI, C.; FRANÇA, T.; VARELLA, T. C. Recursos humanos e gestão do trabalho em saúde: da teoria para a prática. In: FALCÃO, A. et al. (Org.). Observatório de recursos humanos em saúde no Brasil: estudos e análises. v. 2. Rio de Janeiro: Fiocruz, 2004, p. 51-70.

PIERANTONI, C. R.; PORTO, S. M. Estudo sobre formas contratuais dos agentes comunitários de saúde (ACS): modalidades e alternativas de contratação. Cadernos RH Saúde. Brasília, v. 3, n. 1, 2006.

PIRES, D. Reestruturação produtiva e trabalho em saúde no Brasil. São Paulo: Annablume, 1998.

POCHMANN, M. Políticas de emprego e renda no Brasil: algumas considerações. In: BOGUS, L.; PAULINO, A. Y. (Org.). Políticas de emprego, políticas de população e direitos sociais. São Paulo: EDUC, 1997. p. 29-46.

. Traços gerais do movimento de desestruturação do mercado de trabalho brasileiro. Encontro Nacional de Economia. Anais... Recife, 1997.

. O emprego na globalização: a nova divisão internacional do trabalho e os caminhos que o Brasil escolheu. São Paulo: Boitempo, 2002.

POLANYI, K. A grande transformação: as origens de nossa época. Rio de Janeiro: Campus, 1980. SILVA, J. de S.; BARBOSA, J. L. O sentido do trabalho Informal na construção de alternativas socioeconômicas e o seu perfil no Rio de Janeiro. Disponível em: <http://www.iets.inf.br/biblioteca/ O_sentido_do_trabalho_informal_na_construcao_de_alternativas_socioeconomicas_e_o_seu_perfil _no_RJ.PDF>. Acesso em: fev. 2006.

SILVA, P. L. B.; COSTA, N. R. Características do mercado de trabalho no setor saúde na década de 1990: Reflexões. In: NEGRI, B.; FARIA, R.; VIANA, A. L. D. (Org.). Recursos humanos em saúdepolitica, desenvolvimento e mercado de trabalho. Campinas: Unicamp, 2002. p. 275-285.

SINAIS de mercado de trabalho em saúde. Observatório Nescon. Disponível em: <http:// www.observarh.org.br/epsm/interna.php?c=sinais >. Acesso em: 10 ago. 2005.

UNICAMP. Núcleo de Estudos de Políticas Públicas. Avaliação da Implementação do PAB (Relatório de Pesquisa). Campinas. 2000. 


\section{Notas}

${ }^{1}$ Palavra consagrada na década de 70 para designar a situação de um país caracterizada pela estagnação econômica e da produção e ao mesmo tempo pela inflação dos preços.

2 A crise econômica deste período só teve precedentes na grande depressão dos anos 30.

${ }^{3}$ De acordo com Bresser Pereira, “o desmascaramento realizado por Marx de caráter ideológico da Economia Política levou os economistas ortodoxos da segunda metade do século XIX a reformularem a ciência econômica. Surge a Escola Neoclássica, marcada pelos nomes de Menger, Walras, Sevons, Pareto e, principalmente, pela figura dominante de Marshall. Os neoclássicos, em todo o seu trabalho, visam a desenvolver uma ciência "pura", objetiva e "positiva", baseada em os modelos econômicos matemáticos, desvinculada de valores, isenta de influências ideológicas”. (PEREIRA, 1970). Ver também do mesmo autor: Ortodoxos e Histórico-Institucionalistas, 2005.

${ }^{4}$ De acordo com César Benjamin (2004, s/p), "para os neoclássicos, a plena utilização dos fatores de produção disponíveis (entre eles, o trabalho) ocorre quando a remuneração de cada fator corresponde à sua produtividade marginal. Logo, em primeira aproximação, há desemprego (ou seja, subutilização do fator trabalho) quando os trabalhadores insistem em exigir (e, eventualmente, por quaisquer motivos, conseguem obter) salários superiores à produtividade marginal do trabalho. Trata-se, pois, de um fenômeno basicamente voluntário - segundo dizem explicitamente as obras de inspiração neoclássica -, pois em um mercado de trabalho competitivo todos os que aceitam a taxa natural de salário encontram trabalho".

${ }^{5}$ Também chamada de exército industrial de reserva. As formas de superpopulação relativa, ou exército industrial de reserva, assumem periodicamente as três formas seguintes: flutuante, latente e estagnada.

${ }^{6}$ A sociedade pós-industrial é caracterizada por uma sociedade baseada em serviços. Uma transição do sistema produtivo baseado em produção de bens materiais para a produção de bens imateriais e de serviços, com valorização do conhecimento e do trabalho intelectual. Daniel Bell e Alain Touraine profetizaram essa transição já nos anos 60 . Bell construiu um quadro sinóptico comparando as características da sociedade industrial e da pós-industrial. Ver, a respeito, em Masi (2000, p. 48- 53).

${ }^{7}$ O IBGE utiliza o critério de desemprego aberto, no qual somente as pessoas que no período de referência estavam disponíveis para trabalhar, e realmente procuraram trabalho, são consideradas desempregadas.

${ }^{8}$ Refere-se aqui à maior taxa de crescimento, o que não significa que seja este grupamento o maior contingente de trabalhadores desempregados.

${ }^{9}$ Constituído pelas ocupações da administração pública, serviços públicos de saúde, clínicas e ambulatórios (DEDECCA, 2001).

${ }^{10}$ Lei de responsabilidade Fiscal - Lei complementar no. 101, de 4 de maio de 2000.- Lei Complemen$\operatorname{tar} \mathrm{n}^{\circ} .82$, de 27 de março de 1995 - Lei Camata .

${ }^{11}$ Avaliação da Capacidade Gestora de Recursos Humanos em Instâncias Locais de Saúde realizada pela Estação de Trabalho IMS/UERJ da Rede Observatório de Recursos Humanos em Saúde, em 2004. 


\section{Abstract}

Labor Market: reviewing concepts and bringing the health field together. A view on the 1990's

This paper analyzes health labor market in comparison with Brazilian labor market in general. It first presents a theoretical study on the subject, to support debate. The characteristics of the labor market in general are discussed, in an effort to evince if the current stage of lack of structuring measures and of regulation can, in part, be reflected on the configuration of the health sector. It evinces a migratory movement of public jobs from the federal sphere to the municipal one, and shows that, in the 1990's, the health public sector made use of more flexible modalities to recruit health professionals.

> Key words: labor market, health labor market, human resources in health. 